Mr. Cunningham says (p. 367) that my article was as dogmatic as it could possibly be. It was meant to be. It was meant to stir up those who continue to use the old terms " acquired" and "innate" without really bothering much about their signification. It has achieved its object admirably.

$\mathrm{He}$ also says that I assert that there " is no sense in the distinction between acquired characters and innate ones with regard to inheritance" [which I did not say], "that all characters are both acquired and innate" [which I did]; he continues:- "This in the accepted meaning of the words is simply untrue." Well of course it is. My point was that the accepted meaning of the terms was vague, that it had led to confusion, and that it ought to be dropped.

Mr. Cunningham does not follow me. I am willing to admit that that may be my fault. I fully recognise, as he does, that the characters of organisms may be divided into two big categories, which have for a long time been called " acquired" and "innate." But I hold that the difference between these two classes of characters is very inadequately expressed by the terms "acquired" and "innate," and that a much better, though, of course, provisional, classification of characters is into $(a)$ those which owe their existence to the interaction between some innate factor and the stimulus (for want of a better term) of nutrition, and $(b)$ those which owe their existence to the interaction between some innate factor and the stimulus of use or injury.

The view that all characters are acquired during ontogeny as the result of a definite stimulus acting on an innate factor was expressed by Weldon (Biometrika vol. i., p. 367), who has also described (loc. cit.) how he succeeded in preventing the appearance of the amnion in the hen's egg by withholding the necessary stimulus.

A full answer to Mr. Cunningham's letter is quite out of the question, because it would involve a discussion on all the meanings of the terms "innate" and " acquired" and a history of their use, which could not be compressed within the limits of a single number of NATURE. But reference must be made to one of the things "innate," as opposed to acquired, certainly does not mean. What ever it means, it does not mean what it literally means. It does not mean the kind of character one is born with. Before it was known that all organisms develop from a single cell it may have meant that, but now that we know that they do, we regard classifications of characters into those which appear before the act which separates intra-uterine from extra-uterine, and those which appear after it, as interesting from a historical point of view only. Yet in this year 1908 we actually read in a letter to NATURE (I am not quoting from memory) that a Negro "is brown (nor black) when he is born; that is an innate character." The facts are true, of course, but not relevant. The fact that a negro is brown when he happens to be born does not matter. The fact we have to face is that the ovum which gave rise to Booker T. Washington was probably not browner than that which gave rise to George. The statement that the colour of the former is innate does not in the least help us to understand the causes to which the difference between the colours of the two men is due.

A. D. D.

[FurTher space cannot be devoted to this correspondence. -ED.]

\section{The Possibility of Life in Mars.}

THE perseverance with which Prof. Lowell has prosecuted his investigation of the surface markings of Mars compels admiration; the evidence he has brought forward for the objective reality of much of the detail he has shown in his sketches serves to convince many reluctant minds; out the interpretation he has put upon these markings, in terms of phenomena associated with life as we know it on our own planet; requires stronger evidence than he has yet brought forward in view of the considerations that follow.

The blue-green coloration he attributes to vegetation; its change to chocolate-brown to the fading of verdure with the change in the season. If we grant that the conditions on Mars have been possibly such as to allow of the develop- ment of living organisms from inorganic matter, is it likely that the course of evolution has been so exactly similar to that on the earth that a chlorophyll-bearing organism has resulted? Like conditions produce like results-granted; but when one considers the quasifortuitous nature of the conditions determining the characters of those organisms that survive in the process of evolution, the remoteness of the probability that the development of the power of forming chlorophyll should happen twice, in two independent evolutionary systems, seems overwhelming.

Again, Prof. Lowell attributes the markings which he considers irrigation systems to intelligent beings. It is possible that that high degree of adaptability to environment, which we call intelligence, might have evolved independently on two planets, but it seems in a very high degree improbable.

Similarly, other points in his scheme of interpretation may be conceivable, but highly improbable. But the probability of the whole is the continued product of all the independent probabilities! The evidence, then, in favour of Prof. Lowell's views will require to be of a much more overwhelming character to claim the assent of those who appreciate their extreme improbability.

Opposition to the views of Prof. Lowell has generally been based on difficulties regarding the physical condition of Mars. It is the object of this letter to emphasise the far greater improbabilities involved in the biological aspect.

Prof. Lowell attributes the reluctance of many to accept his position to the emotions of men. I venture to think that emotions are in his favour; it is the human desire for an anthropomorphic interpretation of nature-in this case perhaps one should rather say a geomorphic interpretation-that has prompted his views, and but for which they would receive small consideration. $\quad$ C. O. BARTrum.

I2 Heath Mansions, N.W., February i7.

IN Dr. William Lockyer's review of Dr. Russel Wallace's book on the habitability of Mars he refers to Dr. Johnstone Stoney's contention that aqueous vapour cannot exist on a planet of that size because the velocity of the molecules would be too great for its attraction to retain them. I do not know what temperature was assumed in the calculation, but a dozen miles above the surface of the planet the temperature of its atmosphere must approach absolute zero-a condition of things in which even hydrogen would not have the necessary velocity to escape.

The question is an important one for those who are interested in the history of the earth, for, whether we choose the nebular or planetesimal view of its origin, there must have been a time when the attraction it exercised on the outer portion of its atmosphere was far less than at present, and if Dr. Johnstone Stoney were right there would be some difficulty in understanding how any watevapour remained.

Imperial Institute, S.W., February is.

\section{The Stresses in Masonry Dams.}

Prof. Pearson's letter in Nature of February 20 requires little in the way of reply from me, since my essential point is now admitted, viz. that the stresses $x x$ and $\widehat{z z}$ are practically the same in a slab, whether it be free or form part of a complete dam. I should, however like to point out to Prof. Pearson, re his comparison between a parabola and an equivalent sine curve, that at $5^{\circ}$ the ordinate is only one-twelfth the maximum ordinate, so that an error of 30 per cent. in this ordinate is one of but $2 \frac{1}{2}$ per cent. on the maximum, which would be, accordingly, absolutely negligible in practical engineering. As regards the remainder of his letter, engineers have the support of many eminent elasticians in their refusal to accept his and St. Venant's dictum that the maximum stretch is the proper criterion of the safety of a structure. In any case, the true criterion is a question for the engineer and the physicist, and not for the mathematician. The most recent expcriments, I may add, negative Prof. Pearson's views on this head.

83 St. James's Road, Croydon. 